\title{
Effects of oxygen tension, temperature, salinity, and humidity on the survival of two intertidal gammarid amphipods
}

\author{
D. J. Agnew \& A. C. Taylor* \\ Zoology Department, University of Glasgow, Glasgow G12 8QQ. Scotland, United Kingdom
}

\begin{abstract}
Echinogammarus pirloti and E. obtusatus are 2 species of amphipod that inhabit boulder shores. Their distribution on such shores on Great Cumbrae Island, Scotland, was found to be zoned; $E$. obtusatus always occurring from MTL downwards and E. pirloti living between MTL and HWN (summer) or HWS (winter). Previous investigation of this shore established that oxygen tension, temperature, salinity and redox potential were the most variable environmental parameters of the amphipods' understone habitat and that there were considerable differences between upper and lower shore sites. E. pirloti was more tolerant of anoxia, high temperature and low salinity than E. obtusatus. The levels of oxygen tension and temperature that induced physiological 'stress' in the laboratory were similar to those recorded on the shore, but both species were able to survive indefinitely in the lowest salinities recorded on the beach. There was no difference in tolerance of low humidity between the 2 species, and there was similarly no difference between understone humidities recorded on the upper and lower shore. The 'dominant' factors determining zonation on the shore are probably tolerance of oxygen tension and high temperature.
\end{abstract}

\section{INTRODUCTION}

Tolerance of physical 'stress' is one of the most fundamental factors affecting the distributions of shore animals. Recently the ability of different gammarids to survive in low salinity, humidity, oxygen tension $\left(\mathrm{PO}_{2}\right)$ and high temperature has been evaluated (Dorgelo 1974, 1977, Bulnheim 1979, 1984). These investigations, however, have been restricted primarly to amphipods from estuarine habitats, and the responses of animals to the physico-chemical 'stress' gradients prevalent on boulder shores have been largely neglected.

The aim of this work is to provide some information concerning amphipods from such an environment. Boulder shores are widespread in West Scotland and their heterogeneity produces many different microhabitats. These include rock surface, sedimentary, seaweed-related and understone environments. The latter provides shelter for many gammarids when the tide recedes (Jones 1948). Two distinct understone habitat types can be recognised: those understone depressions

\footnotetext{
- To whom all correspondence should be addressed
}

which contain water at low tide ('wet' habitats) and those which drain and provide 'dry' areas of shelter. During low tide amphipods inhabiting understone habitats may therefore be exposed to stresses characteristic of both aquatic and aerial environments, e.g. variations in temperature, salinity, hypoxia, redox potential, $\mathrm{pH}$ and humidity.

The 2 common amphipods Echinogammarus pirloti (Sexton \& Spooner) and E. obtusatus (Dahl) have zoned distributions on boulder shores, with E. pirloti occurring on the upper shore and E. obtusatus occurring below MTL (Sexton \& Spooner 1940, van Maren 1975, Agnew 1985). They are thus convenient species with which to examine the effects of environmental factors on the biota inhabiting boulder shores.

The data here presented were obtained as part of a larger investigation into the physiological ecology of Echinogammarus pirloti and E. obtusatus (Agnew 1985) and the present paper uses information derived from that work. The study was carried out on a boulder shore (Farland Bight) at the south end of Great Cumbrae Island, Firth of Clyde, Scotland. Agnew \& Taylor (1986) have presented some data concerning the understone micro-habitats at various vertically dis- 
placed positions on this beach. In that study we found that, of 6 parameters studied, the $\mathrm{PO}_{2}$, temperature, salinity and Eh of understone habitats showed the greatest seasonal and daily fluctuations, especially during periods of emersion. The differences between the upper and lower shore habitats were considerable; in general the physico-chemical conditions in upper shore understone habitats showed greater fluctuations and the animals inhabiting such sites were subjected to these conditions during low tide for longer periods (up to $9 \mathrm{~h}$ compared to 3 to $4 \mathrm{~h}$ for the lower shore). In contrast to the situation found in crevices on open coast rocky shores (Morton 1954), humidity did not vary between the understone habitats at the upper and lower shore sites. Although very low humidities were recorded at the top of the shore (above the upper level of E. pirloti distribution), humidities were generally benign (>70\% RH) lower down the shore.

Although temperature and salinity tolerances have been studied in amphipods, particularly in estuarine species (Dorgelo 1974, Bulnheim 1979), investigations of low oxygen stress have been largely confined to sediment-dwelling Crustacea and rock pool environments (Thompson \& Pritchard 1969, Theede 1973, Burke 1979). Our study attempts to examine the effects of 4 major environmental factors $\left(\mathrm{PO}_{2}\right.$, temperature, salinity and humidity) on the survival of Echinogammarus pirloti and E. obtusatus in an attempt to determine whether the tolerance to any of these factors could limit amphipod distribution. The effects of Eh were not investigated, partly because of the difficulty of separating the effects of Eh and low oxygen tension, and also because Theede (1973), in an investigation of many different invertebrate species, found that low Eh alone accounted for very little of the mortality of animals subjected to a combination of anoxia and low Eh.

\section{METHODS}

Echinogammarus pirloti and E. obtusatus were collected from cobble shores on Great Cumbrae Isle (O.S. grid reference NS 17325415). Both species were maintained in tanks $(40 \times 25 \times 15 \mathrm{~cm})$ filled to 5 to $10 \mathrm{~cm}$ depth with seawater ( 33 to $34 \%$ ). These were kept in a marine aquarium in Glasgow University Zoology Department for a period of at least $2 \mathrm{wk}$ before any experiments were performed. The amphipods were supplied with stones for cover and decaying algae for food. Water temperature in the tanks was maintained between 12 and $14^{\circ} \mathrm{C}$.

The littoral distribution of the species was determined along a transect at Farland Bight, a cobble shore at the south end of the island, once monthly for $1 \mathrm{yr}$. For consistency, sampling was carried out between neap and spring tides at times when the low tide levels were +0.6 to $0.7 \mathrm{~m}$ above chart datum (C.D.). Eight stations were sampled, at $+1.2,1.5,1.9,2.25,2.4,2.7$. 3.0 and $3.3 \mathrm{~m}$ above C.D. (MHWN $=2.9 \mathrm{~m} \mathrm{C.D.,} \mathrm{MTL}$ $=1.9 \mathrm{~m}$ C.D., MLWN $=1.0 \mathrm{~m}$ C.D.). Amphipods were sampled from beneath cobbles of approximately $20 \mathrm{~cm}$ diameter using a $10 \mathrm{~cm}$ diameter corer. Animals were identified and counted after sorting and preservation in $70 \%$ ethanol.

Temperature. Observations in the laboratory showed that the amphipods survived indefinitely at temperatures of 5 to $20^{\circ} \mathrm{C}$. Recordings in the field (Agnew \& Taylor 1986) showed that temperatures of $25^{\circ} \mathrm{C}$ were reached in the summer. Following these results, survival of Echinogammarus pirloti and E. obtusatus was measured in air and water only at 25 and $30^{\circ} \mathrm{C}$, and specimens were transferred abruptly to these temperatures from the aquarium temperature of 12 to $14^{\circ} \mathrm{C}$. All experiments were performed in water baths set to the required temperature. Specimens were placed individually (adults) or in groups of 3 (juveniles) in test containers. The apparatus for aquatic survival consisted of $10 \mathrm{ml}$ glass vials each covered with a plastic gauze held in place by an elastic band. The vials were immersed in aerated seawater in a small perspex aquarium tank $(20 \times 20 \times 30 \mathrm{~cm})$, itself contained within a water bath.

This method proved unsuitable for juvenile amphipods because they became enmeshed in the gauze and were therefore difficult to observe. Instead, juveniles were placed in small $5 \mathrm{ml}$ vials containing $2 \mathrm{ml}$ seawater which had their apertures sealed with a rubber bung. Two large diameter hypodermic needles $(19 \mathrm{~g})$ were inserted through the bung, one into the water and the other into a small airspace at the top of the vial, and saturated air was bubbled slowly through the vial to aerate the water during the experiment.

To measure their survival in air, individuals were placed in glass specimen tubes $(75 \times 25 \mathrm{~mm})$ together with moist filter paper. Plastic gauze was placed twothirds of the way down the tube (held in place by a ring cut from the lid of the tube) to prevent the specimens crawling out. Finally, damp cotton wool was used to plug the top of the tube and a small (diameter $2 \mathrm{~mm}$ ) plastic tube inserted to maintain aeration. The tubes were then put into a floating test tube rack within a water bath, so that the bottom two-thirds of the tube was immersed. During tests the temperature at the bottom of the tube was found to be the same as that of the water bath.

Anoxia. All experiments were carried out at $15^{\circ} \mathrm{C}$, as this was the environmental temperature during the summer when low oxygen tensions were encountered under stones (Agnew \& Taylor 1986). The understone environment remained anoxic for much of the low tide 
period at this time. Deoxygenated water was obtained by bubbling $\mathrm{N}_{2}$ through a 11 flask of seawater. Specimens were placed in batches of 3 (adults) or 10 (juveniles) in $5 \mathrm{ml}$ vials which were then filled with deoxygenated seawater and a previously-prepared rubber bung inserted. This bung was penetrated by 2 wide-bore hypodermic needles ( $19 \mathrm{~g}$ ) which were then attached to plastic tubes leading from the deoxygenated seawater flask and to a previously calibrated oxygen electrode. The electrode (E5046 Radiometer, Denmark) was encased in a thermostatted cell maintained at $15^{\circ} \mathrm{C}$ and connected to an oxygen meter (Strathkelvin Instruments, Glasgow). When the oxygen tension of the water in the vial had dropped to less than 5 Torr $\left(6.67 \times 10^{2} \mathrm{~Pa}\right)$ the tubes were detached from the hypodermic needles and replaced by small bungs. Previous experiments had established that the water in the vials remained anoxic $(<5$ Torr) for at least $24 \mathrm{~h}$ after bungs were inserted into the needles.

Humidity. Only adult amphipods were tested for their tolerance of low humidities. All experiments were carried out at $10^{\circ} \mathrm{C}$ in a constant temperature room and the humidities were established at this temperature using saturated solutions.

The saturated solutions used and their humidities at $10^{\circ} \mathrm{C}$ were taken from Winston \& Bates (1960) and are given below.

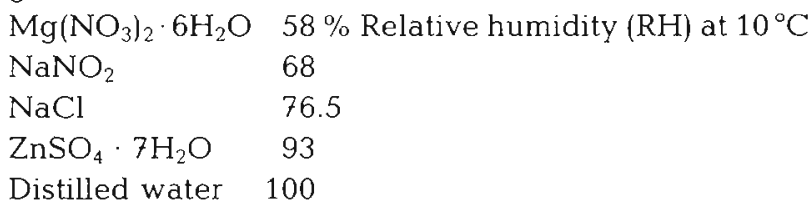

These relative humidities were checked throughout the experiments using a micro-humidity probe (constructed from a design in Unwin 1980) which measured the change in resistance of a potassium acetate droplet with the absorption or release of water in different humidities. This probe was placed in a bung protruding through the metal lid of a Kilner jar. Two extra holes were drilled in the lid, normally closed with bungs, for use in manipulating the apparatus inside the jar with a glass rod and in separating live and dead specimens during an experiment.

Amphipods were superficially dried on filter paper and then placed in one half of a perforated perspex Petri dish (diameter $5 \mathrm{~cm}$ ) which had been previously divided into 2 halves with a plastic baffle. This handling did not appear to affect survival. The Petri dish was mounted on a $3 \mathrm{~cm}$ high perspex cylinder. A perforated perspex lid was put onto the dish to prevent specimens escaping from the chamber and the whole apparatus was placed carefully into the Kilner jar. Because of the numerous perforations in both the dish and the lid there was minimal mixing between the air inside and outside the jar during this operation. Read- ings of the humidity inside the chamber showed that the relative humidity ( $\mathrm{RH}$ ) during this operation did not increase by more than $5 \%$ and returned to the expected humidity within $1 \mathrm{~h}$.

Salinity. Adult amphipods were abruptly subjected to various salinities at $10^{\circ} \mathrm{C}$ in a constant temperature room. The salinities were obtained by diluting aquarium water of known salinity (33\%) with distilled water to produce seawater with salinities of 0 to $1,2,4$, 8 , and $33 \%$. The actual salinity of the water was determined by silver nitrate titration.

Batches of 10 specimens were quickly washed in distilled water, superficially dried on filter paper and introduced into crystallizing dishes (diameter $7 \mathrm{~cm}$ ) filled to a depth of $2 \mathrm{~cm}$ with water at the test salinity. A piece of nylon gauze, rinsed in distilled water, was provided as a substratum for the amphipods. The dish was covered by a Petri dish lid to minimize evaporative loss. Dishes were examined at regular intervals to determine mortality and individuals were removed as they died. As in the previous experiments, death was determined by failure to respond to mechanical stimulation. The salinity was checked during, and at the end of, the experiment.

\section{RESULTS}

\section{Distribution}

Seasonal changes in the distribution patterns of Echinogammarus pirloti and E. obtusatus are shown in Fig. 1. Densities of the E. pirloti populations (approx. 400 to 800 ind stone $e^{-1}$ at the position of maximum density on the shore) were always much greater than

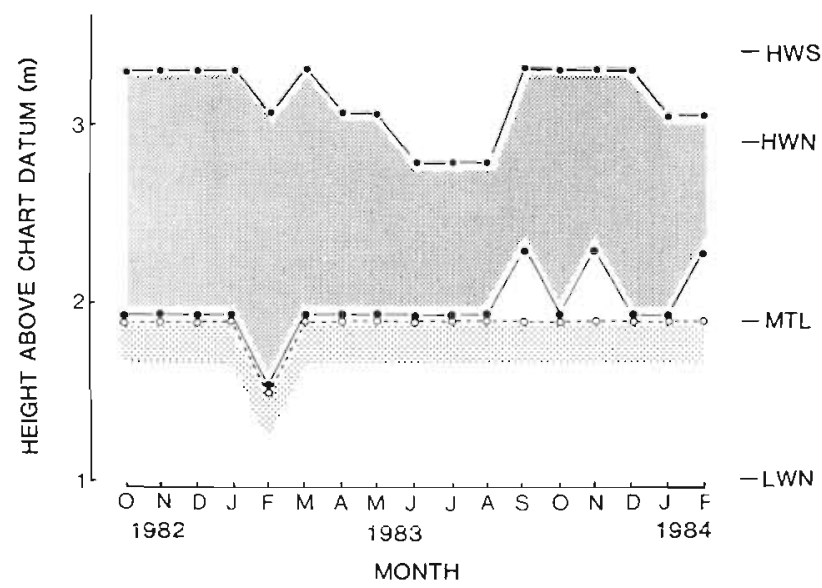

Fig. 1. Distribution of Echinogammarus pirloti (dark shading) and E. obtusatus (light shading) on a cobble shore (Farland Bight, Isle of Cumbrae). Note that the distributions of the 2 species adjoined at the Mean Tide Level. HWS = High Water Spring tides, HWN $=$ High Water Neap tides, MTL = Mean Tide Level, $L W N=$ Low Water Neap tides 
Table 1. Echinogammarus pirloti and E. obtusatus. (a) $\mathrm{LT}_{50}$ times (h) of amphipods exposed to high temperatures $\left(\mathrm{LT}_{50}=\right.$ time to $50 \%$ death). Values given are for a single group of 30 specimens and therefore standard deviations are unavailable. Dry wt. ranges for adults were 7 to $12 \mathrm{mg}$ and for juveniles 1 to $2 \mathrm{mg}$

\begin{tabular}{|ccccc|}
\hline \multirow{2}{*}{ Species } & \multicolumn{2}{c}{$25^{\circ} \mathrm{C}$} & \multicolumn{2}{c|}{$30^{\circ} \mathrm{C}$} \\
& Air & Water & Air & Water \\
\hline E. pirloti & & & & \\
$\quad$ Adults & 140.4 & 63.9 & 5.9 & 8.8 \\
$\quad$ Juveniles & 41.3 & 72.0 & 9.6 & - \\
E. obtusatus & & & & \\
$\quad \begin{array}{l}\text { Adult } \\
\text { Juveniles }\end{array}$ & 48.1 & 45.2 & 0.52 & 3.9 \\
& 47.3 & 48.0 & - & 4.4 \\
\hline
\end{tabular}

(b) Time to first death (h) for specimens exposed to $25^{\circ} \mathrm{C}$ in air and water

\begin{tabular}{|lcc|}
\hline Species & Air & Water \\
\hline E. pirloti & & \\
$\quad$ Adult & 6 & 12 \\
$\quad$ Juveniles & 2 & 24 \\
& & \\
E. obtusatus & 14 & 12 \\
$\quad$ Adult & 24 & 12 \\
Juveniles & & \\
\hline
\end{tabular}

the densities of $E$. obtusatus (10 to 20 ind stone $e^{-1}$ ). Although the position of separation of the 2 species on the shore was consistently at the Mean Tide Level, the upper level of E. pirloti distribution varied with season and was lower in the summer.

\section{Thermal stress}

The survival of 30 amphipods exposed to high temperatures both in air and in water is shown in Table 1. Throughout these experiments there was no significant difference between the survival of males and females of either species (a Chi-squared test carried out on the proportions of males and females alive at a time close to the calculated $\mathrm{LT}_{50}$ gave $\chi^{2}<2.8, \mathrm{P}>0.05$ ). Consequently, in subsequent experiments data for males and females were pooled to produce the results in Table 1. The most striking result of these experiments was the marked difference in thermal tolerance between the 2 species; adult Echinogammarus pirloti were more tolerant of high temperature than E. obtusatus in all cases (Table 1a).

Survival at $25^{\circ} \mathrm{C}$ was greater in air than water for Echinogammarus pirloti but not for E. obtusatus. Con- versely, survival in air was much lower at $30^{\circ} \mathrm{C}$ for both species. The reasons for this difference are unclear. It is unlikely that the specimens were able to benefit from any evaporative cooling in the tubes, a common method of decreasing the effective body temperature (Wilkens \& Fingerman 1965, Ansanullah \& Newell 1977), because the atmosphere was saturated with water vapour.

Interestingly, contrary to the results reviewed by Sprague (1963) and Precht (1973) in which adults were usually more tolerant of high temperature than juveniles, there was generally no difference in the survival of adults and juveniles in these experiments (Table 1a); the exception was the result at $25^{\circ} \mathrm{C}$. In some cases the $\mathrm{LT}_{50}$ 's were greater for juveniles than for adults, but statistical comparisons were not possible because there were no estimates of standard deviation. Times to first death are given in Table $1 \mathrm{~b}$.

\section{Anoxic stress}

Echinogammarus pirloti was much more resistant to anoxia than E. obtusatus (Fig. 2). In addition to having higher $\mathrm{LT}_{50}$ 's (Table $2 \mathrm{a}$ ) the time to first death for adult $E$. pirloti was much longer than for adult E. obtusatus. Despite the significant difference between the tolerance of adults and juveniles, there was no significant difference between the $\mathrm{LT}_{50}$ values for juveniles of the 2 species (Table 2b), although Fig. 2 indicates that juvenile $E$. pirloti had a slightly higher survival than juvenile E. obtusatus. It would appear, therefore, that the marked resistance to anoxia shown by $E$. pirloti

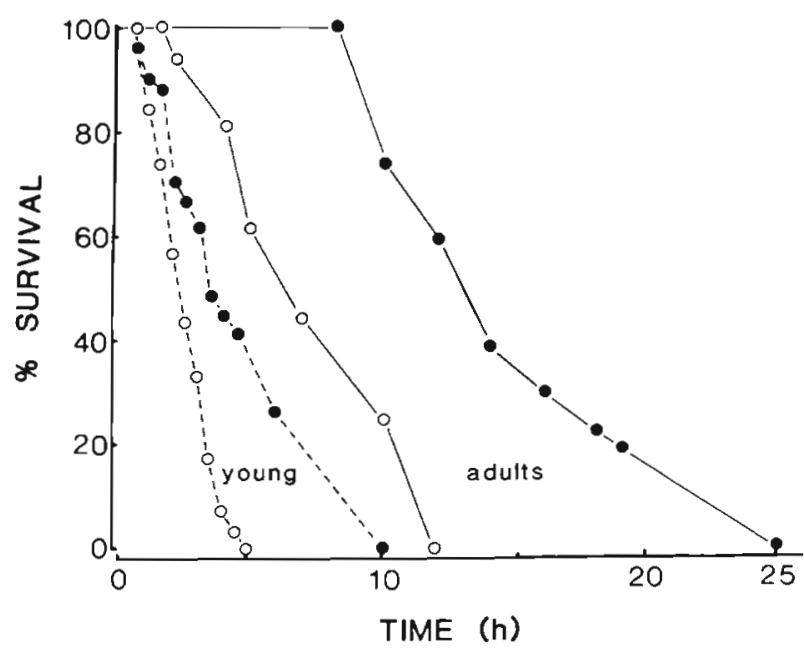

Fig. 2. Survival of Echinogammarus pirloti (-) and E. obtusatus $(O)$ in anoxia at $15^{\circ} \mathrm{C}$. Mean survival plotted of 12 replicates each of 3 adults ( 7 to $12 \mathrm{mg}$ dry wt.) or of 6 replicates each of 10 juveniles ( 1 to $2 \mathrm{mg}$ dry wt.). Results of male and female trials have been pooled 
Table 2. Echinogammarus pirloti and E. obtusatus. (a) $\mathrm{LT}_{50}$ times (h) for groups of 3 adults or 10 juveniles subjected to anoxia $\left(\mathrm{PO}_{2}<5\right.$ Torr) at $15^{\circ} \mathrm{C}$. Values are means with $\mathrm{SD}$ in parentheses and number of replicates in square brackets. Adult and juvenile weights as in Table 1

\begin{tabular}{|lrc|}
\hline Species & Adults & Juveniles \\
\hline E. pirloti & $12.5(3.04)[12]$ & $3.92(0.88)[6]$ \\
E. obtusatus & $6.04(2.10)[12]$ & $2.35(0.61)[3]$ \\
\hline
\end{tabular}

(b) Mann Whitney U test on original data for comparisons of $\mathrm{LT}_{50}$ 's presented in Table 2a. (Sokal \& Rohlf 1973). Tests not significantly different (NS) or different with $\mathrm{P}<0.01\left({ }^{\prime}\right)$ or $\mathrm{P}<0.001(\cdots)$

\begin{tabular}{|c|c|c|c|}
\hline \multirow[t]{2}{*}{ Species } & \multirow{2}{*}{$\begin{array}{l}\text { E. pirloti } \\
\text { Juveniles }\end{array}$} & \multicolumn{2}{|c|}{ E. obtusatus } \\
\hline & & Adults & Juveniles \\
\hline E. pirloti Adults & $\cdots$ & $\cdots$ & $\cdots$ \\
\hline Juveniles & & $\cdots$ & NS \\
\hline E. obtusatus Adults & & & $\cdots$ \\
\hline
\end{tabular}

manifests itself only after the amphipods become adults.

Using the same Mann Whitney test as in Table 2b the $\mathrm{LT}_{50}$ 's of males and females were shown to be not significantly different for either species $(P>0.05)$.

\section{Humidity}

The survival of groups of 10 specimens at different humidities are shown in Fig. 3. As expected, there was a progressive decrease in survival with decreasing relative humidity. $\mathrm{LT}_{50}$ 's showed that survival was not a single function of increasing humidity and that $\mathrm{LT}_{50}$ 's changed most rapidly over the range 70 to $90 \% \mathrm{RH}$ (Fig. 4).

During the initial stages of these experiments, individuals clumped together - only breaking away from the clump just before dying - presumably in an effort to reach a more humid environment. The strategy of group formation probably created a localized area of high humidity around the clump. To investigate the effectiveness of clumping in reducing mortality, different group sizes were put in the apparatus. The results showed that survival increased linearly with group size (Fiq. 5).

\section{Salinity}

Both species demonstrated high degrees of tolerance to low salinities (Table 3) and could be maintained for some weeks in hyposaline conditions above $5 \%$.

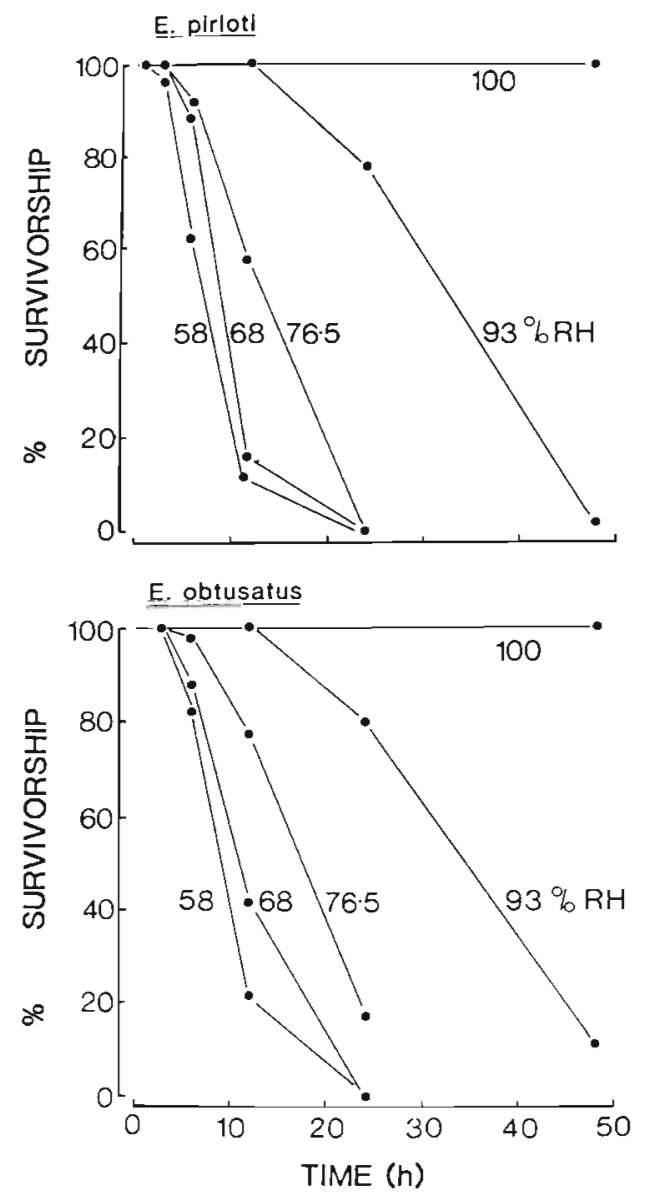

Fig. 3. Survival of Echinogammarus pirloti and E. obtusatus in low humidities. Mean values of 5 replicates (each of 10 specimens) are plotted. Results of male and female trials have been pooled

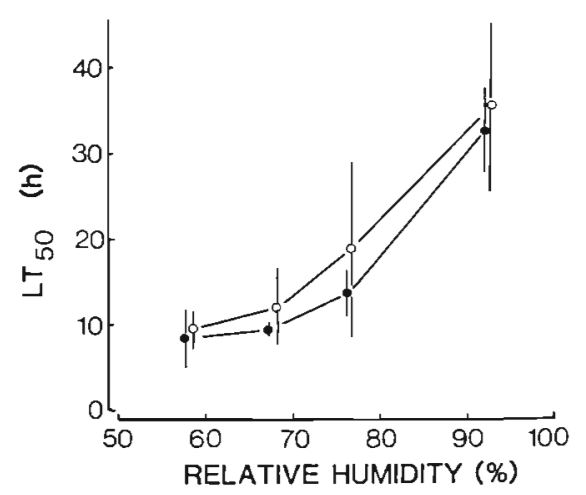

Fig. 4. LT $T_{S u}$ of survival of Echinogammarus pirloti (e) and E. obtusatus $(0)$ in low humidities. Mean values of 5 replicates (each of 10 specimens) are plotted $\pm \mathrm{SD}$

Although Echinogammarus pirloti always had a much higher survival under extremely hyposaline conditions both species were able to tolerate even distilled water $(<1 \%$ ) for long periods of time. 


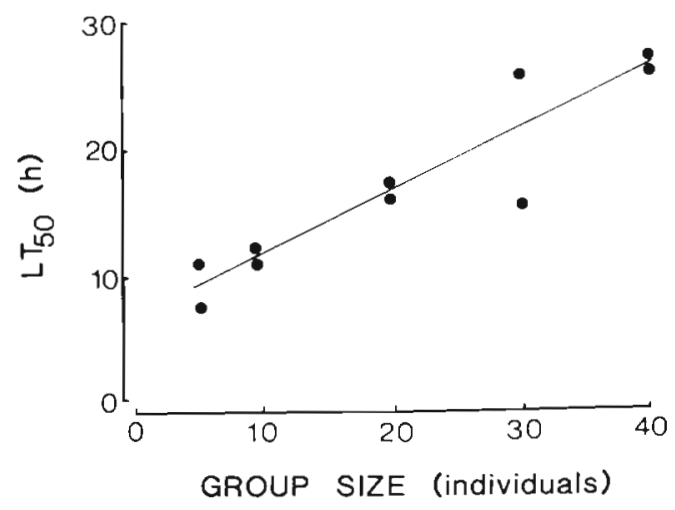

Fig. 5. Echinogammarus pirloti. Relation between $\mathrm{LT}_{50}$ in $68 \% \mathrm{RH}$ and group size. Equation of the line is $L T_{50}=0.49$ (group size) $+6.63(\mathrm{r}=0.923, \mathrm{n}=10)$

Table 3. Echinogammarus pirloti and E. obtusatus. $\mathrm{LT}_{50}$ times (d or h) for groups of 10 adults subjected to hyposaline conditions. Values are means of 7 (E. pirloti) or 6 (E. obtusatus) replicates with $\mathrm{SD}$ in parentheses. Both species survived indefinitely in salinities greater than $5 \%$

\begin{tabular}{|c|c|c|c|c|}
\hline \multirow[t]{2}{*}{ Species } & \multicolumn{4}{|c|}{ Salinity $(\%)$} \\
\hline & $<0.5$ & 1.25 & 2.00 & \\
\hline E. pirloti & $5.64(3.6)$ & $>10$ & $>10$ & (d) \\
\hline E. obtusatus & $4.3 \quad(0.4)$ & $34.7(17.8)$ & $49.7(21.0)$ & (h) \\
\hline
\end{tabular}

\section{DISCUSSION}

A well-described feature of coastal ecology is that where gradients of environmental 'stress' exist species are arranged in a zoned pattern related to their differential physiological tolerances to those conditions. Bulnheim (1979) has shown this to be true for a series of estuarine gammarids. His results demonstrated that these gammarids had different responses to temperature, low $\mathrm{PO}_{2}$ and low humidity, in addition to showing differences in their survival of low salinity. Thus, although salinity was the 'dominant' ecological factor and was used to characterize species of estuarine gammarids in ecological descriptions (Bulnheim 1979), other physico-chemical factors had similar effects on survivorship.

Given this result, and since their vertical distribution on the shore was different, it is not surprising that the 2 Echinogammarus species should show differences in tolerance to a wide range of environmental factors. The high-shore species would be expected to show greater tolerance towards all factors compared with the lowshore species. Identification of the primary or 'dominant' factor influencing animal distributions, however, requires close examination both of the real micro- environment and the responses of the animals to the different physico-chemical stresses.

As stated by Bulnheim (1979) and by many other workers (e.g. McLusky 1981), the dominant physical stress in estuarine systems is salinity. On rocky shores, in contrast, tolerance of humidity and temperature are thought to be more important in limiting species distribution and vertical zonation (Newell 1979, Levinton 1982). Although boulder shores have a superficial similarity to the latter, their environmental conditions are quite distinct, as has been shown by Agnew \& Taylor (1986). Recordings of understone conditions at the study site showed that temperature, $\mathrm{PO}_{2}$ and salinity were likely to have most effect on amphipod survival and zonation. Surprisingly, there appeared to be no difference in understone humidity at different positions on the shore. This result suggested that humidity was comparatively unimportant in determining the zonation of the 2 species. As shown in this paper, Echinogammarus pirloti and E. obtusatus demonstrate differences in their tolerance of high temperature, low oxygen tension and low salinity that are consistent with E. pirloti occupying the more 'stressful' high shore. Under the same conditions E. pirloti could survive emersion for longer than E. obtusatus. Comparison with the results of our earlier study (Agnew 1985), however, shows that in the field only temperature and $\mathrm{PO}_{2}$ ever reached levels where, according to the survival data given here, animals would be physiologically stressed. Temperature often reached 20 to $25^{\circ} \mathrm{C}$ and $\mathrm{PO}_{2}$ was very low, approaching anoxia, for long periods during the summer. The levels attained would be sufficient to result in the death of some individuals since the time to first death under these conditions was usually less than $12 \mathrm{~h}$ (Table $1 \mathrm{~b}$ and Fig. 2). Thus it would appear that temperature and oxygen tension are the 'dominant' physico-chemical factors that affect $E$. pirloti and E. obtusatus on boulder shores.

Conversely, salinities of lower than $7 \%$ were never recorded on our beach. Since both species were able to survive indefinitely at this salinity (Table 3), low salinity is unlikely ever to be of major importance locally in influencing the zonation of the 2 species.

Agnew \& Taylor (1986) failed to find any difference in humidity between the low and high-shore understone habitats at Farland Bight. The corresponding lack of any difference in humidity tolerance between Echinogammarus pirloti and E. obtusatus confirms the hypothesis that differences in tolerance reflect differences in degree of 'stressful' exposure to a particular parameter. Nevertheless, it is interesting that the upper level of distribution of $E$. pirloti was lower in the summer (Fig. 1), at a time when humidities under stones and in a wrack bed within the E. pirloti zone were over $70 \% \mathrm{RH}$. Understone humidity recorded 
further upshore was $50 \%$. According to the results presented here, this latter RH would be 'stressful' for $E$. pirloti and may explain the distribution changes in the summer (Fig. 1).

A further feature that may influence the distribution of Echinogammarus species is their behavioural response to environmental factors. Where humidity was an important environmental stress, the formation of amphipod aggregations could increase survival and thereby affect distribution. Clumping doubtless increases humidity in the micro-environment and underlines the importance that micro-environmental characteristics may have in determining the distribution of amphipods on boulder shores.

Acknowledgements. We would like to thank Dr. P. G. Moore for helpful suggestions concerning the field and laboratory experiments, and for criticizing the manuscript. This work was completed whilst D.J.A. was in receipt of a NERC research studentship.

\section{LITERATURE CITED}

Agnew, D. J. (1985). The comparative ecophysiology of two species of intertidal amphipod. Ph.D. thesis, University of Glasgow

Agnew, D. J., Taylor, A. C. (1986). Seasonal and diurnal fluctuations of some physico-chemical parameters of a boulder shore. Ophelia (in press)

Ansanullah, M., Newell, R. C. (1977). The effects of humidity and temperature on water loss in Carcinus maenas (L.) and Portunus marmoreus (Leach). Comp. Biochem. Physiol. 123: 225-232

Bulnheim, H.-P. (1979). Comparative studies on the physiological ecology of five euryhaline Gammarus species Oecologia (Berl.) 44: 80-86

Bulnheim, H.-P. (1984). Physiological responses of various Gammarus species to environmental stress. Limnologica (Berl.) 15: 461-467

Burke, E. M. (1979). Aerobic and anaerobic metabolism during activity and hypoxia in two species of intertidal crabs Biol. Bull. mar. biol Lab., Woods Hole 156: 157-168

Dorgelo, J. (1974). Comparative ecophysiology of Gammarids from marine, brackish and freshwater habitats exposed to the influence of salinity-temperature combinations. 1. Effects on survival. Hydrobiol. Bull. (Amsterdam) 8: $90-108$

Dorgelo, J. (1977). Comparative ecophysiology of two intertidal Gammarids and the problem of zonation. Crustaceana Suppl. 4: 64-80

Jones, N. S. (1948). The ecology of the Amphipoda of the south of the Isle of Man. J. mar. biol. Ass. U.K. 27: 400-439

Levinton, J. S. (1982). Marine ecology. Prentice-Hall, London

Maren, M. J. van (1975). The biology of Chaetogammarus marinus (Leach) and Eulimnogammarus obtusatus (Dahl) with some notes on the other intertidal gammarid species. Bijdr. Dierk. 45: 205-224

McLusky, D. S. (1981). The estuarine ecosystem. Blackie, London

Morton, J. E. (1954). The crevice fauna of the upper intertidal zone at Wembury. J. mar. biol. Ass. U.K. 33: 187-224

Newell, R. C. (1979). Biology of intertidal animals, 3rd edn. Marine Ecological Surveys Ltd., Faversham

Precht, H. (1973). Limiting temperatures of life functions. In: Precht, H., Christophersen, J., Hensel, H., Larcher, W. (ed.) Temperature and life. Springer-Verlag, Berlin, p. $400-440$

Sexton, E. W., Spooner, G. M. (1940). An account of Marinogammarus (Schellenberg) gen. nov. (Amphipoda), with a description of a new species, $M$. pirloti. J. mar. biol. Ass. U.K. 24: 33-682

Sokal, R. R., Rohlf, F. J. (1973). Introduction to biostatistics. Freeman, San Francisco

Sprague, J. B. (1963). Resistance of four freshwater crustaceans to high lethal temperature and low oxygen. J. Fish. Res. Bd Can. 20: 387-415

Theede, H. (1973). Comparative studies on the resistance of marine bottom invertebrates to oxygen deficiency and hydrogen sulphide. Mar. Biol. 2: 325-337

Thompson, R. K., Pritchard, A. W. (1969). Respiratory adaptations of two burrowing crustaceans Callianassa californiensis and Upogebia pugettensis (Decapoda, Thalassinidea). Biol. Bull. mar. biol. Lab., Woods Hole 136: $274-287$

Unwin, D. M. (1980). Microclimate measurement for ecologists. Academic Press, London

Wilkens, J. L., Fingerman, M. (1965). Heat tolerance and temperature relationships of the fiddler crab Uca pugilator, with reference to body coloration. Biol. Bull. mar. biol. Lab., Woods Hole 128: 133-141

Winston, P. W., Bates, D. H. (1960). Saturated solutions for the control of humidity in biological research. Ecology 41: 232-237 